\title{
2010 Pisacano Scholars
}

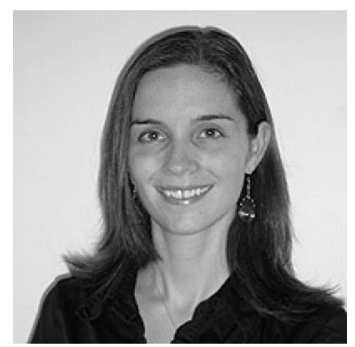

Allana Krolikowski

Allana Krolikowski, a 2010 Pisacano Scholar, is a fourth-year medical student at the University at Buffalo. She graduated from University at Buffalo with a Bachelor of Science in Biomedical Sciences and a Bachelor of Arts in Spanish. While studying abroad during her senior year, she interned for 2 months at a hospital in Cuernavaca, Mexico, where she aided in and observed procedures in the emergency department and assisted in surgeries. After graduation she spent another month as a volunteer, staffing and organizing a medical clinic for the disadvantaged, indigenous population in Palenque, Mexico.

As a medical student, Allana began volunteering with a malaria program in Nyamuswa, Tanzania, distributing mosquito nets and assisting with community education about malaria. After returning home, Allana began serving as cocoordinator of the malaria program. Allana took a year off from medical school and worked in the front office of a family practice office, which serves a diverse, urban, underserved population, including a large population of refugees.

After returning to medical school, Allana conducted a 6-month chart review of patients with hepatitis B who were followed by the practice and later presented her results to the providers. This has led the Burmese community in Buffalo to desire further education about this infection. As an advocate for health care reform, Allana has given several presentations, encouraging other medical students to become more involved in learning about health policy and advocacy. In addition, she has provided listener commentary to a local radio station, lobbied her congressmen at the national level, and participated in rallies for health care reform.

As a family physician, Allana looks forward to providing culturally competent, full-spectrum care in underserved communities in the United States, Africa, and Latin America. She plans to continue her advocacy for health care reform and continue to pursue her interest in languages.

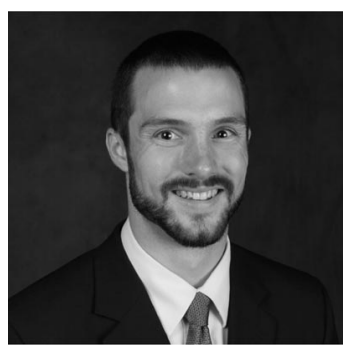

Matthew Malek

Matthew Malek, a 2010 Pisacano Scholar, is a fourth-year medical student at the University of Rochester School of Medicine and Dentistry. He graduated from Middlebury College (VT) with a Bachelor of Arts in Neuroscience. As an undergraduate Matthew volunteered as an emergency medical technician. During his senior year he spent time at the Mother Teresa Home for Sick and Dying Destitutes in Addis Ababa, Ethiopia, assisting with clinic responsibilities and performing hygiene and comfort measures for end-of-life patients.

As a medical student, Matthew spent 2 months in Riobamba, Ecuador, performing baseline research for a water treatment program in an indigenous community. After winning the Offices for Medical Education International Medicine Fellowship, Matthew spent a year living and working in the rural community of San Jose, Honduras, where he served as the field director for the community development project of Shoulder to Shoulder and the University of Rochester Department of Family Medicine. Matthew has presented his research nationally and has spoken about the topic of sustainable community development in various venues. Matthew also cofounded San Jose Partners, a student group devoted to supporting the aforementioned project in San Jose. 
In Rochester, Matthew has served as the coleader of the Physicians for Human Rights student chapter. As president of the local American Medical Student Association chapter, he has coordinated National Primary Care Week and increased membership more than 4-fold. Matthew has also volunteered with numerous local community service projects, including the Health and Wellness Action Committee of the Rochester Children's Zone, Rochester Youth in Motion, and Students of Rochester outreach.

Matthew hopes to increase the presence of family medicine within the global health and development community and plans to spend a significant portion of his career abroad.

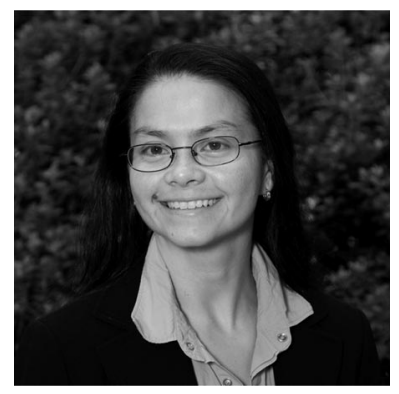

Mayra Alicia Overstreet Galeano

Mayra Alicia Overstreet Galeano, a 2010 Pisacano Scholar, is a fourth-year medical student at the University of North Carolina at Chapel Hill. Alicia graduated from Duke University with a Bachelor of Science in Biology. As an undergraduate, Alicia was awarded a Minority International Research Training grant to work in Moshi, Tanzania, where she helped implement a project to assess a clinical case definition of HIV/AIDS. She later joined the Division of Dermatology as a laboratory technician, where she worked for 7 years after graduation.

After graduating from Duke, Alicia also worked for 8 years as a research associate and data manager in the Children's Environmental Health Initiative at the Duke University Nicholas School of Environment. With the Children's Environmental Health Initiative, Alicia helped shift public health efforts from mitigation to prevention. During this time Alicia also assisted with curriculum development and the planning of a course working with medical Spanish and cross cultural communication at the Duke University Schools of Medicine and Nursing. She also served as a staff member for the course's yearly, 10-day outreach trips to communities in Honduras.

Alicia was selected as one of 20 North Carolina medical school students for the Board of Governors Medical Scholarship, a full-tuition scholarship and stipend awarded to students who are academically qualified, financially worthy, and who have a promising future as a successful physician in North Carolina. Alicia is a founding member of an interdisciplinary program that assesses the household health care needs in the Sahsa community for the Región Autonama del Atlantico Norte in Nicaragua. For the last 2 years Alicia has also served as an interpreter and member of medical teams with the Student Health Action Coalition, a free, student-run clinic for the Chapel Hill-Carrboro community.

Alicia plans to combine practice in a community health center setting with a career in academic family medicine.

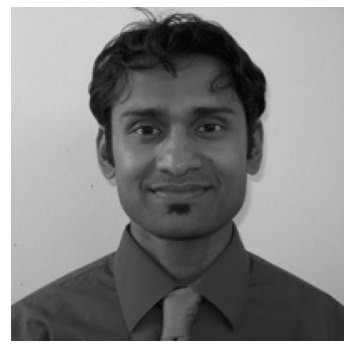

Rohan Radhakrishna

Rohan Radhakrishna, a 2010 Pisacano Scholar, is a final-year student at the University of California San Francisco/Berkeley Joint Medical Program. He recently completed his MS and MPH at Berkeley, focusing on research methodology, human rights, and leadership. Rohan graduated from Stanford University with a Bachelor of Science in $\mathrm{Hu}-$ man Biology and honors in a Latin American Studies minor. As a Fulbright Scholar in Ecuador, he spent 2 years continuing research on indigenous health initiatives, conducting social justice "Reality Tours" for Global Exchange, and training promotores (village health workers). Rohan then worked as the assistant to the United Nations Liaison for Médecins Sans Frontières-Doctors Without Borders in New York City before graduate school.

Rohan recently returned from a gap year in India as a Rotary Ambassadorial Scholar, where he focused on health journalism and storytelling for advocacy. As a medical and public health student, Rohan cofounded his school's Students Taking Ac- 
tion Now Darfur group and helped coordinate the free "Suitcase Clinic" for the underserved. He also organized students to advocate for universal health care in California through teach-ins and lobby days in Sacramento. At the national level Rohan has served as the Health and Human Rights Coordinator for the American Medical Students Association and organized the Global Health Leadership Institute in Washington, DC. For his MPH, Rohan spent 2 summers in Northern Uganda as a Human Rights Fellow researching the health effects of forced displacement among war-affected youth. His project won the Lancet Outstanding Global Health Research Award in addition to several poster prizes. He also worked as a humanitarian health consultant for UNICEF and the Norwegian Refugee Council addressing issues of shelter, child protection, and population movement.

Rohan's vision of his future career involves grappling with health policy issues and innovating community-based care models that empower patients to be proactive and preventive in their health care.

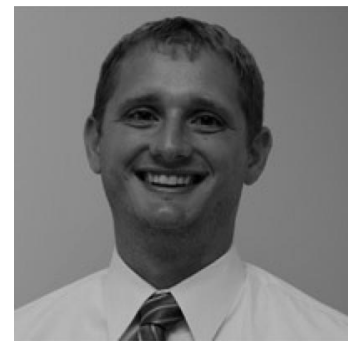

\section{Mark Stoltenberg}

Mark Stoltenberg, a 2010 Pisacano Scholar, is a fourth-year medical student at Loyola University, Chicago, Stritch School of Medicine, where he also received a Dean's scholarship to complete his master's in bioethics and health policy. He graduated from Duke University with a Bachelor of Arts in
Religion. From the age of 13 through college Mark volunteered at a children's hospital. During his senior year he participated in service trips to Salem, West Virginia, and Managua, Nicaragua, both poverty stricken areas.

During his first 2 years of medical school, Mark created a family advocacy program that connects local underserved families with medical students through a new service-learning curriculum. Mark and a few of his classmates chose to move into the underserved community and developed a surveybased research study in conjunction with the department of preventive medicine to better assess the community of Maywood, IL. Through his research, Mark hopes to give the department a better understanding of the local community that will more accurately direct future projects and initiatives.

As an Albert Schweitzer fellow, Mark recently began a self-designed, year-long fellowship. This fellowship will allow Mark to commit a year to act as the medical coordinator for a 13-village clinic system in rural Bolivia, which was started by an attending physician from Loyola and her husband 9 years ago. During his year there, Mark will be coordinating the public health projects conducted by the clinic, fostering communication between the clinic and the 13 villages it serves, and assisting in patient care alongside visiting attending physicians. Once instituted, Mark plans to make his position a permanent Global Health Fellowship.

Mark plans to remain in academic medicine and continue working with the various projects and communities he has connected with while in medical school.

Jane Ireland

American Board of Family Medicine 